\title{
The idea of a 'spoon': semantics, prehistory, and cultural logic
}

\author{
Anna Wierzbicka* \\ School of Literature, Languages and Linguistics, Baldessin Precinct Building (\#110), Australian National University, ACT 0200, Australia
}

\section{A R T I C L E I N F O}

\section{Article history:}

Received 12 March 2014

Accepted 16 August 2014

Available online 20 September 2014

\section{Keywords:}

Lexicography and conceptual analysis

Cultural logic of artefact concepts

NSM

Relevance of semantics to prehistory

Relevance of semantics to history of food

Semantics as a key to cultural history

\begin{abstract}
A B S T R A C T
The invention of the spoon may not be quite as ground-breaking in human history as the invention of the wheel or the needle, but arguably it is also a significant conceptual (as well as technological) event. It has been claimed that "all people in the world use spoons", that "spoons have been used as eating utensils since Paleolithic times", that chimpanzees in Gombe use "sort-of-spoons"... Can we draw a line, in a principled and precise way, between 'spoons' and 'sort-of' spoons'? For example, is the so-called "Chinese spoon" (tāngchí) a 'spoon'? Can we explain why a 'tāngchî' is different in many respects from a ('European') 'spoon' and similar in others? Most importantly, perhaps, can we reconstruct with any plausibility the conceptual model in the minds of the first prehistoric inventors of 'spoons'? Can we tell in what part of the world they lived, when they lived, what they wanted to eat with those first 'spoons', and why they found 'spoons' more suited to their needs than something like 'tāngchí' ('Chinese spoons')? These are some of the questions that this paper will address, using as a tool NSM techniques of semantic and conceptual analysis.
\end{abstract}

(c) 2014 Published by Elsevier Ltd.

\section{Introduction: a methodology for interpreting 'cultural kinds' concepts}

I will start with three examples of sentences with the word spoon coming from different periods of English.

1. Supper was announced. The move began and Miss Bates might be heard from that moment, without interruption till her being seated at table and taking up her spoon. [Context: eating soup] (Jane Austen, 1833)

2. ... Father Joseph lifted the cover and ladled the soup into the plates, a dark onion soup with croutons. The Bishop tasted it critically and smiled at his companion. After the spoon had travelled to his lips a few times, he put it down ... (Willa Cather, 1927)

3. Sitting at the breakfast table after the grace, he watched MacAllister dip his spoon in his porridge and then in his buttermilk and slurp the contents noisily (Adair, 1993).

The spoons used in these three different periods may have been somewhat different, but the idea reflected in them all, and associated with words such as soup, porridge, dip, slurp and table appears to be the same.

\footnotetext{
* Tel.: +61 261253353.

E-mail address: anna.wierzbicka@anu.edu.au.
} 
The title of this paper echoes that of Cardinal John Henry Newman's, “The idea of a university" (2009). 'University' is, obviously, a big idea, and 'spoon' may seem to be a very small one at best. Is it an idea at all? Isn't a spoon a thing rather than an idea?

Well, yes and no. A spoon is a thing, but so is a fork or a ladle. To decide whether an object is or is not a spoon we need to understand the meaning of the word spoon, and this meaning points to an idea, not a thing.

As I argued thirty years ago in relation to 'cup' and 'mug', words naming different kinds of artefacts in particular languages embody culture-specific ideas of great complexity and intricate internal logic:

To state the meaning of a word it is not sufficient to study its applicability to things; what one must do above all is to study the structure of the concept which underlies and explains that applicability.

In the case of words describing natural kinds or kinds or human artefacts, to understand the structure of the concept means to describe fully and accurately the IDEA (not just the visual image) of a typical representative of the kind, i.e. the prototype. And to describe it fully and accurately we have to discover the internal logic of the concept. This is best done not through interviews, not through laboratory experiments, and not through reports of casual, superficial impressions or intuitions (either of 'informants' or of the analyst himself), but through METHODICAL INTROSPECTION and THINKING. (Wierzbicka, 1984: 213; see also Wierzbicka, 1985)

The present study of 'spoons' builds on the same methodology on which my study of 'cups' and 'mugs' built thirty years ago, and also draws on the refinements of that methodology in the intervening decades. It is the methodology known as NSM: the use of the Natural Semantic Metalanguage (NSM) based in its lexicon and grammar on the intersection of all (sampled) natural languages. The three key notions of this approach most relevant to the present study are 1 . semantic primes, 2 . semantic molecules, and 3. semantic templates.

Before briefly explaining these three notions (which have been extensively discussed elsewhere, see e.g. Goddard, 2011, 2012), I would like to say that from an NSM point of view, thinking methodically about 'spoons' (or any other cultural kinds) involves not only a systematic use of semantic primes, molecules and templates but also a systematic NON-USE of any words chosen ad hoc, any technical words or ordinary words used in some technical sense, and any words which don't have exact equivalents in the language whose terms are being scrutinised (Cf. Wierzbicka, 2014).

This excludes, for example, the use of the word bowl to describe part of a spoon, as English dictionaries often do, or reliance on words like implement or utensil, which are not used in everyday language. It also excludes the used of the English word spoon to state the meaning of the Chinese word tāngchí (so-called "Chinese spoon"), because Chinese doesn't have a word equivalent in meaning to the English word spoon (just as English doesn't have a word equivalent in meaning to tāngchí). These exclusions set the NSM apart from other approaches to semantics no less than its key notions of primes, molecules, and templates, to which I will turn in the next section.

The reason for these exclusions lies in the strong cultural focus of NSM research. Words are seen in NSM research as vehicles of culture. To try to explore the meaning of the Chinese word tângchí, or the internal logic of this cultural kind, through English words like spoon or implement, would mean to distort this concept's cultural logic, that is, its links with Chinese cultural practices and ways of thinking. The same applies to the English word spoon itself: to try to explore the concept of 'spoon' through technical words would mean to distort its cultural logic, that is, its place in the thinking and the cultural practices of the inventors and users of 'spoons'.

\section{Semantic primes, molecules and templates}

\subsection{Semantic primes}

"Semantic primes" are meanings which are so simple that they cannot be defined in terms of any other simpler ones. Decades of intralinguistic and crosslinguistic investigations carried out within the NSM framework (see e.g. Goddard and Wierzbicka, 1994, 2002, 2014) have led to the conclusion that there are 65 such meanings expressed as words (or wordlike elements) in all languages. For example, the words Do and HAPPEN in sentences like "What are you doing?" or "What happened to you?" cannot be replaced in these sentences with any phrases composed of words more elementary than Do and HAPPEN themselves. NSM research indicates that such questions can be rendered in any language, and that the words Do and HAPPEN are, so to speak, "universal words", as well as being semantic primes. The full repertoire of such primes, in its most recent version, is given in Table 1.

\footnotetext{
1 The term “cultural logic” comes from John Gumperz's 1982 book Discourse Strategies. It was first used in NSM research in my 1991 book Cross-Cultural Pragmatics, where I contrasted it with George Lakoff's notion of "natural logic":

'Natural logic' provides a considerable range of options. The choices embodied in individual languages reflect not only 'natural logic', and not only a combination of 'natural logic' with historical accidents. They reflect also what Gumperz (1982: 182) aptly calls 'cultural logic'. (Wierzbicka, 2003 [1991]: 62)
} 
Table 1

Semantic primes (English exponents), grouped into 12 related categories.

\begin{tabular}{ll}
\hline 1. & I, YOU, SOMEONE, SOMETHING THING, PEOPLE, BODY, KIND, PART \\
2. & THIS, THE SAME, OTHER \\
3. & ONE, TWO, MUCH $\sim$ MANY, LITTLE $\sim$ FEW, SOME, ALL \\
4. & GOOD, BAD, BIG, SMALL \\
5. & THINK, KNOW, WANT, DON'T WANT, FEEL, SEE, HEAR \\
6. & SAY, WORDS, TRUE \\
7. & DO, HAPPEN, MOVE \\
8. & BE (SOMEWHERE), THERE IS, BE (SOMEONE/SOMETHING), BE (SOMEONE'S) \\
9. & LIVE, DIE \\
10. & WHEN $\sim$ TIME, NOW, BEFORE, AFTER, A LONG TIME, A SHORT TIME, FOR SOME TIME, MOMENT \\
11. & WHERE PLACE, HERE, ABOVE, BELOW, FAR, NEAR, SIDE, INSIDE, TOUCH \\
12. & NOT, MAYBE, CAN, BECAUSE, IF, VERY, MORE, LIKE \\
\hline
\end{tabular}

\subsection{Semantic molecules}

Not all concepts can be resolved directly into semantic primes, and evidence suggests that many complex concepts are built out of simpler building blocks which are in turn built of other, still simpler, ones. For example, the concept of 'spoon' includes in its meaning the concept 'eat'. It would not make sense to try to explicate the meaning of 'spoon' exclusively in terms of primes if the concept 'eat' - which is not a prime - functions as an integrated unit within the concept of 'spoon'. Such integrated units of meaning are called "semantic molecules" and are marked in NSM explications with symbol (m).

Cross-linguistic research carried out within the NSM framework shows that different languages have different sets of semantic molecules, but also, that some molecules are universal or near-universal. In the present study of 'spoons' I will use 18 molecules, about half of which appear to be universal or near universal. They are: hands, mouth, fingers; top, bottom, egg; water; ground; eat, hold; long, round, flat, thick; hard, hot, smooth, and last but not least, 'thing'.

\subsection{Semantic templates}

In my 1984 study of 'cups' and 'mugs', I wrote:

Linear order and spatial proximity of components. The components which make up the concept of cup are interrelated, and can all be explained in terms of the function. But it is not only the SET of components underlying this concept that is nonarbitrary and forms a structured whole; so too the ORDER of the components in that structured whole is non-arbitrary and should be reflected by the order of components in the explication. (...) Much more work on the semantics of words for concrete objects is needed before the optimal schema of an explication can be proposed with full confidence. From the work which I have done so far, however, it would appear that names of human artefacts require the following schema, in this order:

category (a kind of thing made by people)

purpose (relative to situation)

material

shape

size

(...) The schema suggested here is not meant as a merely technical device for constructing readable explications. It constitutes a hypothesis about cognitive structure. I presume that since 'simple' everyday concepts like cup are in fact formidably complex, as my exceedingly long explications indicate, they must have some devices embodied in their structure which would enable people to use them without difficultly. A constant schema governing the order of components would constitute an ideal device of this kind. (p. 237-238)

During the three decades since this was written, it emerged that the optimal schema (or template) for cultural kinds such as 'cups' and 'spoons' is somewhat different. In the explications developed in the present paper I will follow the template used by Cliff Goddard in his Semantic Analysis (2011) for 'cups' and 'mugs'. It looks like this (in this order):

functional category

size

material

parts (design)

setting

use sequence

artifact status 


\section{The basic meaning of 'spoon'}

According to the Longman Dictionary of the English Language, a 'spoon' is "an eating, cooking, or serving implement consisting of a small shallow round or oval bowl with a handle"; and according to Collins English Dictionary, it is "an object shaped like a small shallow bowl with a long handle, which is used for eating, mixing, stirring, and serving food". Both these definitions present 'spoons' as multifunctional, while at the same time attributing to them a stable structure, with two differently shaped parts. They also both try to say something about the size of these two parts, calling one of them "small”.

But since the functions of the 'spoon' are (supposedly) multiple, nothing in these definitions hints at a unifying idea, and so the apparent stability of shape and size is puzzling; and the description of one of two parts as "small" is somewhat meaningless without any indication of what the relevant standard of size might be.

In this paper, I am going to argue that the category of 'spoons' is based on a unifying idea, and that this idea is a rich and complex one - no less so than the idea of a 'university'. To capture this idea, however, we need to recognize one function of objects called 'spoons' as the primary one, and the main meaning of the word spoon based on that function as distinct from a number of extended uses. Clearly, this primary function is not mixing, stirring or serving food, but eating. This is reflected in the fact that English speakers do speak, in some situations, of a "serving spoon", but not of an "eating spoon": unless the word is used elliptically, when it is used without qualifiers, spoon refers to an "eating utensil", not to a serving, mixing or stirring one.

As I will try to show in detail, the main meaning of spoon, from which all the others are derived, envisages one person who wants to eat something of a particular type, in a particular setting, and in a particular way. To be able to fit this idea in their makers' mind, 'spoons' (in the primary, non-extended sense of the word) have to meet certain conditions regarding their size, material, and structure. In the next section, "Function, size, material”, I will discuss these conditions, trying to show that they are not arbitrary but are interrelated and follow a certain logic. This logic will be further explored and documented in the sections entitled "Setting" and "Use sequence".

The key point is that the function of 'cultural kind' concepts like 'spoon' cannot be fully understood if it is not considered in relation to the setting in which a given kind of artefact is intended to be used. It is a point which I strongly emphasised thirty years ago in my critique of William Labov's analysis of the meaning of cup:

To understand words for human artefacts one must first of all understand the reason for producing those artefacts that is, one must understand their function. True, Labov's 'definition' does refer to a function of cups (or at least to their use), but the treatment is hardly exhaustive. According to his formula cups are used for consumption of hot liquid food. (...) But Labov (1978) says, or implies, the same above mugs. If the function of cups is the same as that of mugs, why should their form be different?

I would suggest that the function of mugs and cups is different and that all the other differences between the concepts 'cup' and 'mug' follow simply from this basic difference in their function. To understand that basic difference in function, one must see the function as relative to a prototypical situation in which objects of each kind are mean to be used. (For an insightful discussion of the relevance of the prototypical situation for meaning, see Fillmore, 1975, 1977.) (Wierzbicka, 1984: 214)

As we will see, what applies to 'cups' and 'mugs', applies also to 'spoons'.

\section{Distinguishing 'spoons' from 'sort-of-spoons'}

Before embarking on an in-depth analysis of the basic meaning of spoon, I would like to consider the idea of 'spoon' from a broader cross-cultural and cross-temporal perspective, starting with two quotes from an article by Bee Wilson, the author of “Consider the Fork: A History of How we Cook and Eat" (2012): "Spoons hold up a mirror to the surrounding culture precisely because they are universal. There are fork cultures and there are chopstick cultures, but all the people of the world use spoons. (...) Every human society has spoons of one kind or another."

So 'spoons' are variable yet universal. But 'spoons' in what sense? For a semanticist, the key question here is how to distinguish 'spoons' from 'sort-of-spoons'. If we don't do that, the statement that "spoons are universal" loses any clear content. Wilson writes:

In the 1960s, Jane Goddall saw chimpanzees fashioning sort-of-spoons from blades of grass, to make up easier for them to slurp up termites. In the distant past, humans lashed shells onto sticks and used them to consume foods too liquid to be eaten with fingers. (...) At different periods, people favored various spoons, depending on what they most liked to eat. (Wilson, 2012)

In order to distinguish "various spoons" from "sort-of-spoons" we need to identify a unifying idea which would both explain the constant features of what speakers of English call 'spoons' (in the primary sense of the word) and be compatible with their diversity.

The history of English knows a number of phrases, and even words, referring to what was regarded at different times as 'spoons', among them, most notably, "Puritans" and "triffids". "Puritans" appeared in England at the time of the republican Commonwealth government of Oliver Cromwell. According to Wilson, they had an egg-shaped rounded part, which replaced 
the fig-shaped rounded part of the previous English silver 'spoons', and a plain handle, which replaced the ornate stem of those earlier silver 'spoons'. To quote Wilson again:

The biggest change with the Puritan spoon was its handle, which was entirely unadorned. It had no decorative "knop" on the end. Over the previous few centuries, silversmiths lavished great artistry on a part of the spoon we would now consider almost irrelevant (...) None of these decorative spoons found favor during the Commonwealth, when excessive decoration of any kind, particularly religious, was disapproved of. The Roundheads [Cromwell's supporters] lopped the heads off spoons just as they lopped off the king's head.

Yet with the restoration of the monarchy, the Puritan spoon disappeared almost overnight. In Wilson's words, “politically, no one wanted to be seen eating dinner with a Roundhead spoon". The "Puritan spoons" were then replaced (at least among the well-to-do people) with "triffids", which came to England from France together with the newly crowned kind, returned from his exile on the Continent.

If we assume that different as they were from each other, early English silver 'spoons' were 'spoons' in the same sense in which "Puritans" and "triffids" were 'spoons', and in which 21st-century eating utensils used in countries like Britain, US, and Australia for eating soup are 'spoons', we need to be able to specify what we mean by spoon in a unified way, consistent with the variation, but not disjunctive (this.. or this.. or this... etc.). We also need to decide what to do with statements like the following:

... all the peoples of the world use spoons. The particular form they take is therefore very revealing: a pretty Chinese porcelain blue-and-white spoon for wonton soup is part of an entirely different culture of eating than (... ) the ladlelike wooden spoons used in poor European households to eat soup from a communal pot... (Wilson, 2012)

Is it true that all the peoples of the world use spoons? Is it true that the "Chinese spoon" is a 'spoon' in the same sense of the word in which some speakers of English eat porridge with a 'spoon' in the 21st century in Britain or Australia? And that so is the "ladle-like wooden spoon used in poor European households to eat soup" (not from a communal pot but from individual bowls, as in Pieter Brueghel the Elder's 16th-century painting "Peasant Wedding")?

In this paper, I will argue that there is a specifiable unitary idea that fits early English silver 'spoons', "Puritan spoons", "triffids", wooden peasant spoons like those shown in "Peasant Wedding", and also what is called spoon in modern English, including, for example, the novels of Jane Austen (1833), Willa Cather (1927), and Adair (1993). When we pinpoint the idea, however, in an NSM explication of 'spoon', with the degree of precision afforded by the NSM methodology, we find that while this unitary sense of spoon can accommodate wooden peasant 'spoons' like those shown in the "Peasant Wedding", it cannot accommodate "Chinese spoons" used for wonton soup. The line between "various spoons" and "sort-of-spoons" runs here. As I will argue at the end of the paper, it may be, ultimately, a line between civilizations based on barley and wheat - which Diamond (1997) calls "the founding crops" of the Fertile Crescent in the Near East and western Asia - and those based, at an early stage, on rice, such as China.

\title{
5. Function, size, material
}

The first thing to note about the concept of 'spoons' is that it stands for a category of things recognised as a distinct "kind of thing" by speakers of English. The basis for singling out this category lies in its usefulness to people in many situations. The question is: what do those situations have in common? The Oxford English Dictionary tries to answer this question as follows: "[a spoon is] a utensil consisting essentially of a straight handle with an enlarged and hollowed end-piece (the bowl), used for conveying soft or liquid food to the mouth", but the disjunction "soft or liquid" admits to a failure to capture a unifying idea.

From this point of view, Bee Wilson's formulation (linked with the distant past) is more satisfactory: "In the distant past, humans lashed shells onto sticks and used them to consume foods too liquid to be eaten with fingers". This is at least unitary, and clearly on the right track, provided that we can explain more precisely and more clearly what it would mean "to be too liquid to be eaten with fingers". Drawing on NSM experience with other areas of lexical semantics (Goddard, in press), I would suggest that while Wilson's reference to fingers (or perhaps hands) should be kept, the characterisation of the food to be eaten with 'spoons' as "too liquid" should be replaced with “can move like water moves”. The soup to be eaten with a 'spoon' does not have to be liquid, and porridge is not liquid, but all soups, and porridge, too, "can move like water moves". This leads us to the following (initial) formulation of the basis on which 'spoons' are singled out by speakers of English as a distinct functional category:

\author{
FUNCTIONAL CATEGORY (Version A) \\ things(m) of one kind \\ often someone does something with a thing $(\mathrm{m})$ of this kind \\ when this someone is eating(m) something if it is like this: \\ this something can move like water(m) moves \\ because of this, this someone can't hold(m) this something with the hands(m)
}

For many speakers of English in the 21st century the "semi-liquid" character of certain foods may indeed be the most salient (if not the only) raîson d'être of 'spoons'. Relatedly, for some people, prototypical foods to be eaten with 'spoons' are cornflakes, yoghurt, custard and ice cream (which can melt). 
Such a focus on cold (and often sweet) foods as the prototypes of what people need 'spoons' for reflects, I believe, a cultural change which came to the Anglosphere with refrigeration. Some aspects of present-day 'spoons' make sense only in relation to the old prototypical 'spoon-foods', that is, soup (hot soup) and porridge (hot porridge). But if there is a new, 'postrefrigeration' meaning of the English word spoon, the older meaning shared by early English silver 'spoons', "Puritans", "triffids", wooden peasant 'spoons' and 20th century factory-produced metal 'spoons' (as in 'cutlery: knife, fork, and spoon') is still part of the passive competence of present-day English speakers, preserved, inter alia, in the meaning of the measure term "table spoon".

So the meaning of the English word spoon as it was used for the last 500 years at least (and for many speakers of English still is) includes a reference to something very hot. Accordingly, the first segment of the explication of this meaning would be a somewhat expanded version of the one stated earlier.

\author{
[A] FUNCTIONAL CATEGORY (Version B, expanded) \\ things(m) of one kind \\ often someone does something with a thing(m) of this kind \\ when this someone is eating(m) something if it is like this: \\ this something can move like water(m) moves, this something can be very hot(m) \\ because of this, this someone can't hold(m) this something with the hands(m)
}

The 'spoons' that speakers of English used for many centuries appear to have had the same essential function as the eating utensil with which the biblical Esau was conveying his "mess of potage" from a bowl (or possibly, pot) to his mouth: it was an important implement with the help of which people could satisfy their hunger by eating some basic food - hot, nourishing, and accessible to everyone. A poor man's food, as well as a rich man's food. For a long time, the prototypical food of this kind was probably a grain-food of some kind, such as porridge or 'kasha', which has been for a thousand years the basic food in Russia.

It seems likely that the modern practice of eating cereals, with a 'spoon', for breakfast, which is wide spread in the modern Anglosphere, continues the old tradition of eating hot porridge, with a spoon, for breakfast - and the shape and size of the modern 'spoon' with which breakfast cereals are usually eaten makes sense as a utensil for eating semi-liquid hot porridge.

It is certainly not an accident that breakfast cereals are not eaten in the Anglosphere with an implement shaped like the "Chinese spoon", of which more will be said shortly - an eating utensil which, arguably, makes sense in the context of the Chinese "rice culture" (a point to which I will return later).

Be it as it may, it is important to emphasise that the "functional category" in the explication of spoon developed here is formulated as a prototype, not a necessary condition: often, someone eats something with a 'spoon' when this something is hot and semi-liquid. In 21st century English as it is used in Britain, Australia or the US, the expression hot soup doesn't have the same status as cold soup: roughly, cold soup is a kind of soup which - contrary to expectations - is served cold. By contrast, hot in hot soup refers only to the soup's temperature, not to what kind of soup it is.

Effectively, then, a 'spoon' provides a means for carrying some food like porridge or soup from a container (now, usually a bowl, in the past, also a plate) to the mouth in small instalments, without touching this food with the hand, and being able to control its passage the whole time (for example, to make sure that it doesn't spill).

If they are to be able to fulfil their basic function of enabling people to eat foods that are semi-liquid and hot, 'spoons' cannot be very big or very heavy: the eating person has to be able to hold a spoon comfortably in one hand for some time, while moving the hand repeatedly in a controlled way. This leads us to the following portrayal of a 'spoon's size:

\title{
[B] SIZE
}

things(m) of this kind are not big

someone can hold(m) a thing $(\mathrm{m})$ of this kind with one hand(m) for some time as this someone wants

when this someone moves this hand(m) as this someone wants

The expected use of 'spoons' dictates also the material from which they are made: it cannot be paper, straw or glass, for example, it needs to be something hard, sturdy and smooth (comfortable for both the hand and the mouth to touch). In modern times, this material is often metal. In the past, it was often wood.

\section{[C] MATERIAL}

things(m) of this kind are made(m) of something hard(m)

this something is something $\operatorname{smooth}(\mathrm{m})$

\section{Design (Parts)}

The design of a spoon, simple as it may seem at first sight, is packed with thought and meaning - as one becomes aware when one tries to unpack it all.

To begin with, a spoon has two parts, very different in shape. One of these two parts is long and can be held with one hand in a way that ensures full control of how the spoon moves (on its way from the bowl or plate to the mouth). The other part is 
open at the top, so that the food can easily get into it when it is put in the bowl (or plate), and it is rounded, so that it can get easily and comfortably into the mouth.

Perhaps the most intriguing aspect of the design of the 'spoon' is the fact that the shape of the rounded part is typically oval rather than round (although it can be round too). This preference for an oval shape suggests that the rounded part of the 'spoon' is not meant to be fully inside the eating person's mouth. Rather, the intention is for the tip to go into the mouth first, followed by some other adjacent parts of the rounded part, but not by all the rest of that part.

The elongated shape of the rounded part of the 'spoon' allows the eating person to introduce the (hot) food into the mouth slowly and gradually. This is so because by putting the tip of the 'spoon' into one's mouth one can introduce, at first, a very small amount of the (hot) food into the mouth. After a moment, one can raise the hand-held part of the 'spoon' so that the other end of the rounded part is above the tip. When this happens, all the (hot) food inside the rounded part can 'slide' easily and gradually into the mouth without the whole rounded part having to be inside the mouth.

The significance of the oval (i.e. 'egg-like') shape of the rounded part of a prototypical 'spoon' becomes clearer when we consider so-called 'teaspoons' and 'dessert spoons', whose rounded part is virtually never exactly round. The elongated shape of the rounded part makes it easy for the tip of such a 'little spoon' to be introduced into the mouth as it were experimentally: to test the taste of what one is about to put inside one's mouth, or perhaps to introduce it into the mouth gradually, savouring each small quantity before swallowing it.

With a normal size 'spoon' (such as spoons used for porridge and soup) such testing and experimentation is not envisaged, but the idea that a shape which is both rounded and elongated makes it easy to introduce the tip of the rounded part of the 'spoon' into the mouth is relevant here too, because such a shape allows for the 'spoon' to be introduced into the mouth gradually. It is easier and more comfortable for the mouth to take in only a small part of the rounded part of the 'spoon', which is quite large in comparison with the mouth, and yet thanks to such a shape one can get (after a very short time) the benefit of a full spoonful of the food without either stretching one's mouth uncomfortably or burning oneself.

This conjecture is corroborated by the shape of the Russian 'spoon', which is, traditionally, used above all for eating kasha and which is always round, not oval. The importance of kasha in Russian culture can hardly be overestimated, and can be compared with the importance of rice in Chinese culture. This importance is reflected in the (rhyming) proverb "shchi da kasha pishcha nasza" ("cabbage soup and kasha are our foods'), and also in sayings such as "malo kashi el”, literally "he has eaten little kasha [in his life]' (i.e. he is young and inexperienced), and "sapogi kashi prosjat", literally 'his boots are asking for kasha' (i.e. have gaping holes at the toes).

So kasha is a basic food, and a lozhka 'spoon' is a basic tool for eating this life-sustaining food; and this basic tool is round, not oval. This is consistent with the fact that kasha is thick, certainly thicker than porridge, and so it is normally not as hot as porridge: the hot water in the semi-liquid food is always hotter than the solid content (for example, in the Russian cabbage soup, the water is always hotter than the cabbage). Accordingly, a traditional Russian 'spoon' is round and doesn't have a tip because in this case there is not the same need for a slow and gradual entry of the content as there is in the case of porridge.

We must ask at this point: is a Russian 'spoon' really a 'spoon', in the same sense of the word in which an oval 'spoon' is a 'spoon'? The matter requires further consideration, but in my opinion, it probably is - and in any case, the round shape as such doesn't disqualify it from being a 'spoon' in the same sense because English 'spoons' can also be round. Accordingly, in the description of the two parts of a 'spoon' given below I have referred to the oval shape as typical rather than constant.

[D] PARTS

a thing $(\mathrm{m})$ of this kind has two parts

one of these two parts is not like the other

one of these two parts is long(m)

when someone is eating $(\mathrm{m})$ something, this someone can hold(m) this part of a thing

-the long part

of this kind with some fingers(m) of one hand(m) in some places

the other part of a thing $(\mathrm{m})$ of this kind is like the bottom(m) part of something round(m), at the same time, it often is like the bottom(m) part of an $\operatorname{egg}(\mathrm{m})$

when this $\operatorname{egg}(\mathrm{m})$ is on the ground(m)

this other part of a thing $(\mathrm{m})$ if this kind doesn't have a top(m) part

there can be something like water(m) inside this part of a thing $(\mathrm{m})$ of this kind

this part is not very big, at the same time, it is not small

part of it can be inside someone's mouth(m) for a short time

\section{Setting and use sequence}

All this may seem quite complex, and it is - and yet this is not the whole story. Neither the shape nor the size of the two parts of a spoon can be fully understood until we take into account the setting in which spoons are expected to be used. The importance of the setting can best be appreciated if we compare 'spoons', in the sense of the English word spoon, with those "Chinese spoons", or tāngchí, of which Wikipedia says that "it is a type of spoon used in Chinese cuisine, with a short, thick 
handle extending directly from a deep flat bowl". Why should the handle of a 'spoon' be longer than that of a 'tāngchí' "Chinese spoon")? Clearly, the answer lies in the different settings in which these two types of implements are intended to be used.

Both spoons and tängchí envisage a situation when food (which is likely to be hot) is neither fully solid nor fully liquid, and is 'contained' in something like a bowl. But a 'tāngchí' envisages a person holding a small 'bowl' in one hand and moving the 'spoon' across the relatively short distance between the hand-held bowl and the mouth. On the other hand, the idea of a 'spoon' envisages a situation where the bowl is for some time in one place, in modern times, typically, on a table, and is not as close to the eating person's mouth as a bowl held in one's hand can be.

So the distance that an English 'spoon' travels from the bowl to the mouth is greater than that travelled by a 'tāngchí'. This explains why the handle of a 'spoon' is longer than that of a 'tāngchí'. It is true that there is also another way of using 'tāngchî': with the bowl on the table, a tängchí held in one hand and a pair of chopsticks in another, and the eating person hunched over the bowl, using both the tängchí and the chopsticks, without holding the bowl. But in this - less typical - setting, the mouth is still very close to the bowl, so here, too, the difference in the distance between the mouth and the bowl explains the difference in the length of the handle.

Presumably, then, the handle of a typical English 'spoon' is as long as necessary for the eating person to be able to reach the (hot) food in a bowl placed on a table (or some other raised surface) when one is sitting close to that table. (One wouldn't want it to be any longer because one needs to move the hand repeatedly, while holding the spoon with the semi-liquid food in it, and to be able to be in control of that movement. Furthermore, while one doesn't need to touch the bowl the whole time (while eating), one does need to be able to touch it whenever one wants to - for example, to tilt it slightly as the amount of the food in it decreases.)

\section{[E] SETTING}

when someone is doing something with a thing $(\mathrm{m})$ of this kind because this someone is eating $(\mathrm{m})$ something, it is like this:

this something is for some time inside a thing $(\mathrm{m})$ of another kind -bowl this thing $(\mathrm{m})$ of another kind is like the bottom(m) part of something round(m), it doesn't have a top(m) part

this thing $(\mathrm{m})$ of another kind is for some time in the same place, -table the bottom(m) part of this thing $(\mathrm{m})$ touches something in this place

it can be in this place for some time like something can be in the same place for some time if it is on the ground(m)

during this time, this someone's hands(m) can touch this thing $(\mathrm{m})$ of another kind on all sides if this someone wants it

The next part of the template for artefacts (of the kind comparable to 'spoons') is called "the use sequence". In the case of 'spoons', this segment too, is long, and apart from the framing components at the beginning and at the end, falls naturally into two parts. These two parts correspond to the two main kinds of movements of the hand on which eating something with a 'spoon' relies. Roughly speaking, first the hand goes down (so that the 'spoon' touches the food in the bowl and 'takes in' a small portion of it), and then, the 'spoon' goes up, to that the small portion of the food travels to the eating person's mouth. At that point, the tip of the rounded (but probably elongated) part is inside the mouth and the hand holding the 'spoon' turns a little, making all the soup contained in the rounded part to move out of it and into the person's mouth.

\section{[F] USE SEQUENCE}

when someone is doing something with a thing $(\mathrm{m})$ of this kind

because this someone is eating $(\mathrm{m})$ something, it happens like this:

at some time, this someone holds(m) this thing $(\mathrm{m})$ of one kind with one hand(m)

-hand moves down at that time, this someone moves this hand(m) in one way

because of this, this hand $(\mathrm{m})$ is for a short time

below the place where it was before

at that time, one of the two parts of this thing $(\mathrm{m})$ of one kind

is for a short time inside this thing $(\mathrm{m})$ of another kind

because of this, this part of this thing $(\mathrm{m})$ of one kind touches this something

inside this thing $(\mathrm{m})$ of another kind

at that time, a little of this something is inside this part of this thing $(\mathrm{m})$ of one kind

after this, this someone moves the hand( $\mathrm{m})$ in another way

-hand moves up

because of this, this part of a thing $(\mathrm{m})$ of one kind is for a short time

above the place where it was before

after this, part of this part of this thing $(\mathrm{m})$ of one kind

is for a short time inside this someone's mouth(m) 
at that time, this someone does something with the hand(m)

because of this, after this, this something inside this part of this thing $(\mathrm{m})$ of one kind is not inside this part anymore

it is inside this someone's mouth(m)

it happens like this many times

The last part of the template is "artefact status": it is essential to the idea of the 'spoon' that 'spoons' are made by (some) people, for the use of (many) people:

\title{
[G] ARTEFACT STATUS
}

many people want to do something with things(m) of this kind at many times

because of this, some people make(m) things(m) of this kind

\section{Spoons vs. tāngchí: a comparison}

The best way of validating the analysis of the 'spoon' idea presented here is, I think, to develop further the comparison between 'spoons' and so-called 'Chinese spoons' (tāngchí) using the same template, focussing on the differences, and discussing the cultural logic behind the contrasting formulations in each part of the template. As Jaqueline Newman (2004) says in her book Food Culture in China, "Chinese spoons are different from Western ones in size, shape, and material. They hold about twice as much and have higher sides, and most are ceramic". (p. 107) I will begin my comparison, though, not with size, shape and material, but with the conceptualisation of the function, from the insider's perspective.

The starting point for the exploration of 'tāngchí' must be the fact that tāng means something like 'soup', without however matching the meaning of the English word soup exactly. Rather, the word implies a type of food ("Chinese soup") that includes, in addition to water, many diverse pieces of solid food (such as vegetables and meat). To quote my Chinese colleague Zhengdao Ye (personal email, 20/1/2014):

Chinese tāng is different from the western soup. Chinese tāng is water+all kinds of things; the Chiense spoon is very useful is getting those things so that one can have those things and the water at the same time. A soup without anything in it is called qingtang [plain soup]. The kind of thick western soup [pumpkin soup, potato soup] is called geng.

Thus, the main difference between the foods intended to be eaten with 'spoons' and those eaten with tāngchí is, roughly speaking, the difference between foods that are semi-liquid (in the case of 'spoon') and those that are mixed (in the ase of tāngchí). The English soup cannot be held with the fingers because, like porridge, it "moves like water can move". The Chinese 'tāng', on the other hand, cannot be held because part of it is water. This suggests the following formula for the "functional category" segment in the template of 'tāngchí':

\section{[A'] FUNCTIONAL CATEGORY (tāngchî) things(m) of one kind \\ often someone does something with a thing $(\mathrm{m})$ of this kind when this someone is eating $(\mathrm{m})$ something if it is like this: this something is hot(m), some of it can move like water(m) moves because of this, this someone can't hold(m) this something with the hands(m)}

The difference is in the fourth line: "this something can move like water(m) moves" in 'spoons' vs. "parts of this something can move like water(m) moves in 'tāngchí'.

Turning now to the "size" segment, 'tāngchí' are shorter than (prototypical) 'spoons'. The reason for the size of 'tāngchí' will be explored further in relation with their design and typical setting, but the general standard of size (which is related to both the setting and the use) can be identified at the outset: one can control a 'tāngchí' (full of soup) for some time by holding it with some fingers (in one place). In the case of 'spoons', the standard of size is linked with the hand: one can control a 'spoon' (full of something like soup or porridge) for some time while holding it with one hand.

\author{
[B'] SIZE (tāngchî) \\ things(m) of this kind are not big \\ someone can hold $(\mathrm{m})$ a thing $(\mathrm{m})$ of this kind with some fingers(m) of one hand(m) for some time \\ as this someone wants \\ when this someone moves this hand(m) as this someone wants
}

Here, the difference lies in line 2: "with some fingers of one hand in" 'tāngchí' vs. "with one hand" in 'spoons'.

As for the material, both 'spoons' and 'tāngchí' need to be made of something hard and smooth; prototypically, however, 'tāngchí' are made of china, not of metal (or, in the past, wood) like spoons. They are a little less sturdy, but the risk of falling on the ground is probably less pronounced than in the case of 'spoons' (which have to travel further between the food and the mouth). Hence the difference between 'hard' in the case of 'spoons' and "hard, not very hard" in the case of 'tāngchí'. 
[C'] MATERIAL (tāngchí)

things(m) of this kind are made of something hard(m), not very hard(m)

this something is something smooth(m), often it is china(m)

The most complex and 'hidden' differences between the two “cultural kinds”, 'spoons' and 'tāngchí', pertain to their design. Like a 'spoon', a 'tāngchí' has two parts, but the contrast in shape between these two parts is not nearly as pronounced as in the case of a 'spoon'.

The part of a 'tāngchí' which is long in shape is, as the article in Wikipedia puts it, "short and thick". This fits in with the way a 'tāngchí' is normally held: although it is relatively short, it is held with some fingers (rather than with two fingers) because it is thick; but it is held in one place rather than in some places because it is short. The hand-held part of a 'spoon' is both thinner and longer; so while it, too, requires the support of some fingers (rather than just two), these fingers are usually spread on the handle, touching it in some places (the index finger and the thumb hold it in one place, while the middle finger is extended below it).

The 'long' part of a 'tāngchí' needs to be thick to be sturdy enough to provide the necessary support for carrying the food contained in the other part of the 'tāngchí' to the mouth. But it is 'thick' in only one sense of the word 'thick': it is not bulky and often it is so to speak 'hollow' (forming as it were a natural extension of the rounded part, and not being clearly separate from it as the handle of a 'spoon' is). Accordingly, when the fingers (some fingers) are holding this long part of a 'tāngchí' in one place, one of these fingers can be touching this part inside this part. (This is impossible with a 'spoon', whose handle is rather thin).

As for the rounded part of a 'tāngchí', it has a flat bottom to accomodate the pieces of solid food present in the "Chinese soup". Consequently, it is deeper than a 'spoon', which tends to be shallow in the middle and very shallow near the edges because it is expected to be inside the eating person's mouth and must not be uncomfortable for the mouth. At the same time, the relatively shallow shape of this part of a 'spoon' makes it possible for the food inside it to get easily out of it, over the edges, and into the eating person's mouth.

[D'] PARTS (tāngchí)

a thing $(\mathrm{m})$ of this kind has two parts

people can think about these two parts like this: "these two parts are like one thing(m)"

one of these two parts is long $(\mathrm{m})$

at the same time, it is thick $(\mathrm{m})$

someone can hold(m) this part of a thing $(\mathrm{m})$ of this kind with some of the fingers $(\mathrm{m})$

of one hand $(\mathrm{m})$ in one place

the other part of a thing $(\mathrm{m})$ of this kind doesn't have a top(m) part

its bottom(m) part is flat $(\mathrm{m})$

the parts on all sides of the bottom(m) part are like parts of something round(m)

there can be something like water $(\mathrm{m})$ inside this part of a thing $(\mathrm{m})$ of this kind

at the same time, many small things(m) can be inside this part of a thing $(\mathrm{m})$ of this kind

-long part

-the other part

The typical setting in which 'tāngchí' are used has already been discussed in connection with the typical context of use of 'spoons'. It is portrayed more precisely in the following part of the explications:

[E'] SETTING (tāngchî)

when someone is doing something with a thing $(\mathrm{m})$ of this kind

because this someone is eating $(\mathrm{m})$ something, it is like this:

this something is for some time inside a thing $(\mathrm{m})$ of another kind -bowl

this something of another kind is like the bottom(m) part of something

round $(\mathrm{m})$,

it doesn't have a top(m) part

this someone can hold(m) this thing(m) of another kind with one hand(m)

for some time when there is something hot(m) inside it

-hand-held

Turning now to the "use sequence", we will note that here, too, the hand moves repeatedly in two different ways - but not "down" and "up", as in the case of 'spoon'. If the bowl is held in the left hand, and the 'tāngchí' in the right hand, the movement of the right hand is not simply 'down' and 'up' because it is also lateral (from right to left), although it can be 'down' and 'up' if the bowl is on the table and the eater is hunched over the bowl. Clearly, from a conceptual point of view, the direction of the movement of the 'tāngchí' is not specified, unlike in the case of the 'spoon'. What is specified is the third component of the use sequence, which doesn't involve a movement of the hand but the action of the mouth: the eater does something with the mouth that causes the soup to get inside the mouth, without any part of the 'tāngchí' going inside of it: 
[F'] USE SEQUENCE (tāngchî)

when someone is doing something with a thing $(\mathrm{m})$ of this kind

because this someone is eating $(\mathrm{m})$ something, it happens like this:

at some time, this someone holds $(\mathrm{m})$ this thing $(\mathrm{m})$ of one kind with some fingers $(m)$ of one hand $(m)$

-hand moves one way

at that time, this someone moves this hand(m) in one way

because of this, one of the two parts of this thing $(\mathrm{m})$ of one kind is for a short time inside this thing $(\mathrm{m})$ of another kind

because of this, this part of this thing $(\mathrm{m})$ of one kind touches this something inside this thing $(\mathrm{m})$ of another kind

at that time, a little of this something is inside this part of this thing(m) of one kind

after this, this someone moves the hand(m) in another way

-hand moves another way

because of this, after this, this part of this thing $(\mathrm{m})$ of one kind

is for a short time near this someone's mouth(m),

it touches this someone's mouth(m)

at that time, this someone does something with the mouth (m)

because of this, something happens to this something inside this part of this thing $(\mathrm{m})$ of one kind

after this, this something is not inside this part of this thing $(\mathrm{m})$ of one kind anymore,

it is inside this someone's mouth(m)

it happens like this many times

The final segment of the explication, "artefact status" is the same in the case of 'tāngchí' and 'spoons':

\section{$\left[\mathrm{G}^{\prime}\right]$ ARTEFACT STATUS}

many people want to do something with things(m) of this kind at many times

because of this, some people make(m) things(m) of this kind

\section{Full explications of 'spoons' and 'tāngchí'}

In this section, I will present full explications of the two concepts, 'spoons' and 'tāngchí', in accordance with the step by step analysis which has gone before. These explications are not contrastive: each presents the concept from a native speaker's point of view, not from the perspective of someone who wants to compare the two. Since the two explications follow the same template, however, it is easy to compare them in any respect that one wants to. (A keen reader may find it interesting to read these, carefully, from beginning to end, but a less patient reader can simply skip them.)

The length of these explications shows that both 'spoons' and 'tāngchí' encapsulate in them very complex concepts. They also make it clear that while there is a considerable overlap between the two, each concept is different. Speaking of 'tāngchí' as "Chinese spoons" may be convenient for practical purposes but we should not allow ourselves to be deceived by this formulation: to think of 'tāngchí' as "Chinese spoons" is like thinking of 'spoons' as "English tāngchí". If we want to understand ways of thinking crystallised in these two words, we should not treat one of them as a default concept and the other one, as a modification of it. Each of them embodies a way of thinking shaped by a particular history, culture, geographical and biological environment, and way of life.

\section{spoons}

things(m) of one kind

often someone does something with a thing(m) of this kind

FUNCTIONAL

when this someone is eating $(m)$ something if it is like this:

CATEGORY

this something can move like water(m) moves, this something can be very hot(m)

because of this, this someone can't hold(m) this something with the hands(m) 
when this someone moves this hand(m) as this someone wants

things of things(m) kind are made(m) of something hard(m)

MATERIAL

this something is something $\operatorname{smooth}(\mathrm{m})$

a thing $(\mathrm{m})$ of this kind has two parts,

PARTS

one of these two parts is not like the other

one of these two parts is long(m)

when someone is eating $(\mathrm{m})$ something, this someone can hold(m) this part of a thing of this kind

with some fingers $(\mathrm{m})$ of one hand( $\mathrm{m})$ in some places

the other part of a thing $(\mathrm{m})$ of this kind is like the bottom(m) part of something round(m),

at the same time, often it is like the bottom $(\mathrm{m})$ part of an $\operatorname{egg}(\mathrm{m})$

when it is on the ground(m)

this other part of a thing if this kind doesn't have a top(m) part

there can be something like water(m) inside this part of a thing $(\mathrm{m})$ of this kind

this part is not very big, at the same time, it is not small

part of it can be inside someone's mouth(m) for a short time

when someone is doing something with a thing $(\mathrm{m})$ of this kind

because this someone is eating $(\mathrm{m})$ something, it is like this:

this something is for some time inside a thing $(\mathrm{m})$ of another kind

this thing of another kind is like the bottom(m) part of something round(m),

it doesn't have a top(m) part

this thing $(\mathrm{m})$ of another kind is for some time in the same place,

the bottom(m) part of this thing $(\mathrm{m})$ touches something in this place

it can be in this place for some time

like something can be in the same place for some time

if it is on the ground(m)

during this time, this someone's hands $(\mathrm{m})$ can touch this thing $(\mathrm{m})$ of another kind

on all sides if this someone wants it

when someone is doing something with a thing $(\mathrm{m})$ of this kind

because this someone is eating $(\mathrm{m})$ something, it happens like this:

at some time, this someone holds $(\mathrm{m})$ this thing $(\mathrm{m})$ of one kind with one hand $(\mathrm{m})$

at that time, this someone moves this hand(m) in one way

because of this, this hand(m) is for a short time

below the place where it was before

at that time, one of the two parts of this thing(m) of one kind

is for a short time inside this thing $(\mathrm{m})$ of another kind

because of this, this part of this thing $(\mathrm{m})$ of one kind touches this something

inside this thing $(\mathrm{m})$ of another kind

at that time, a little of this something is inside this part of this thing(m) of one kind

after this, this someone moves the hand(m) in another way

because of this, this part of a thing $(\mathrm{m})$ of one kind is for a short time above the place where it was before

after this, part of this part of this thing $(\mathrm{m})$ of one kind

is for a short time inside this someone's mouth $(\mathrm{m})$

at that time, this someone does something with the hand(m)

because of this, after this, this something

inside this part of this thing $(\mathrm{m})$ of one kind is not inside this part anymore,

it is inside this someone's mouth(m)

it happens like this many times

many people want to do something with things(m) of this kind at many times

ARTEFACT STATUS because of this, some people make(m) things of this kind

-hand moves up 


\section{tāngchí}

things $(\mathrm{m})$ of one kind

FUNCTIONAL CATEGORY

often someone does something with a thing $(\mathrm{m})$ of this kind

when this someone is eating $(\mathrm{m})$ something if it is like this:

this something is hot(m), some of it can move like water(m) moves

because of this, this someone can't hold(m) this something with the hands(m)

things(m) of this kind are not big

SIZE

someone can hold(m) a thing(m) of this kind with some fingers (m) of one hand(m)

for some time, as this someone wants

when this someone moves this hand(m) as this someone wants

things $(\mathrm{m})$ of this kind are made of something hard(m), not very hard(m)

this something is something smooth $(\mathrm{m})$, often it is china(m)

a thing $(\mathrm{m})$ of this kind has two parts

people can think about these two parts like this: "these two parts are like one

thing(m)"

one of these two parts is long(m)

at the same time, it is thick $(\mathrm{m})$

someone can hold(m) this part of a thing $(\mathrm{m})$ of this kind with some of the fingers $(\mathrm{m})$ of one hand(m) in one place

the other part of a thing $(\mathrm{m})$ of this kind doesn't have a top(m) part

its bottom(m) part is flat $(\mathrm{m})$

the parts on all sides of the bottom(m) part are like parts of something round(m) there can be something like water(m) inside this part of a thing $(\mathrm{m})$ of this kind at the same time, many small things $(\mathrm{m})$ can be inside this part of a thing $(\mathrm{m})$ of this kind

when someone is doing something with a thing $(\mathrm{m})$ of this kind

because this someone is eating $(\mathrm{m})$ something, it is like this:

this something is for some time inside a thing $(\mathrm{m})$ of another kind

this something of another kind is like the bottom(m) part of something

round(m), it doesn't have a top (m) part

this someone can hold(m) this thing(m) of another kind with one hand(m)

for some time when there is something hot(m) inside it

MATERIAL

PARTS

-long part

-the other part

SETTING

-bowl

when someone is doing something with a thing $(\mathrm{m})$ of this kind

because this someone is eating $(\mathrm{m})$ something, it happens like this:

at some time, this someone holds(m) this thing $(\mathrm{m})$ of one kind with some fingers $(\mathrm{m})$ of one hand(m)

at that time, this someone moves this hand(m) in one way

because of this, one of the two parts of this thing $(\mathrm{m})$ of one kind

is for a short time inside this thing $(\mathrm{m})$ of another kind

because of this, this part of this thing $(\mathrm{m})$ of one kind touches this something inside this thing $(\mathrm{m})$ of another kind

at that time, a little of this something is inside this part of this thing(m) of one kind

after this, this someone moves the hand(m) in another way

because of this, after this, this part of this thing(m) of one kind

is for a short time near this someone's mouth(m), it touches this

someone's mouth(m)

at that time, this someone does something with the mouth(m)

because of this, something happens to this something inside this part

after this, this something is not inside this part

of this thing of one kind anymore,

-doing something with the

mouth

-hand moves another way

-hand-held

USE SEQUENCE

-hand moves one way 
it is inside this someone's mouth(m)

it happens like this many times

many people want to do something with things(m) of this kind at many times

because of this, some people make(m) things(m) of this kind

ARTIFACT STATUS

\section{Why 'spoons'?}

Why do European languages have a word like 'spoon', whereas Chinese languages don't (but have instead a word like 'tāngchí')? As I foreshadowed at the outset, I am going to argue that the differences between the two concepts, 'spoon' and 'tāngchí', are linked with the different "founding crops" of the civilizations within which these concepts arose: in one case, wheat and barley, and in the other, rice (replacing the earlier millet, a staple crop of early Chinese agriculture; see e.g. Fernandez-Armesto, 2001; Diamond, 1997, p. 310).

As already discussed, there appears to be a link between the origin of 'spoons' and the introduction of farming in western Asia and then Europe. As historian Fernandez-Armesto writes in his acclaimed book Food: A History (2001), "Farming seems to have started independently, in so many different parts of the world, in such widely contrasting climatic conditions, that it appears pointless to try to insist on any climatic prerequisites" (p. 97). At the same time, it seems clear that in different parts of the world farming developed in different ways, depending (at least partly), on local climatic conditions. In a section entitled "The Great Grasses" (of the chapter entitled "The Edible Earth") Fernandez-Armesto writes:

The most influential crops farmers developed were the seed-rich grasses which store oil, starch and protein in their grains. Despite the enormous and growing importance of a few kinds of such grasses, of which wheat is the most prominent, (...) grasslands have normally been composed of varieties inedible to man, but suitable for other animals with ruminant habits or better digestions.

The developments of rye, barley, millet, rice, maize and wheat are therefore among the most spectacular achievements of humankind: turning grasses - which nature seemed to have designated as the food of other, better-equipped species - into the staple fodder of non-ruminants like ourselves. Other important plants in the repertoire include buckwheat, oats and sorghum; but the big six are special because whole civilizations have relied for sustenance on each of them. (pp. 100-101)

My hypothesis is that the concept of 'spoon', too, depends on the rise of "the great grasses" - and in particular, two of them: barley and wheat (or possibly three: those two and rye).

According to evolutionary biologist Jared Diamond, the early domestication of three cereals: barley and two varieties of wheat, had a huge impact on the rise of agriculture and food products in the Fertile Crescent of the ancient Near East. Wheat became the basis of bread cultures, and barley (along with peas and lentils) one of the most significant types of readily available cooked food. Presumably, such cooked food required pottery - and spoons. Diamond (1997: 362) dates the adoption of plant domestication in the Fertile Crescent at, approximately, $8500 \mathrm{BC}$, and the adoption of pottery, $7000 \mathrm{BC}$. (Regrettably, he doesn't mention spoons or any other eating utensils.)

Speaking of the advantages of wheat and barley (as well as peas), which launched food production in the Fertile Crescent, Diamond writes (p. 124):

[they] arose from wild ancestors offering many advantages. They were already edible and gave high yields in the wild. They were easily grown, merely by being sown or planted. They grew quickly and could be harvested within a few months of sowing, a big advantage for incipient farmers still on the borderline between nomadic hunters and settled villages. They could be readily stored (...). They were mostly self-pollinating: that is, the crop varieties could pollinate themselves and pass on their own desirable genes unchanged, instead of having to hybridize with other varieties less useful to humans.

In his Food: A History Fernandez-Armesto also emphasises the importance of barley and its great "ecological tolerance":

... barley has tended to assume huge importance as a staple for human consumption wherever conditions are too hostile for other grains. But it makes poor bread and so tends to get eaten as unground grains in soups and stews (...). Even so, it has been the basic sustenance of great civilizations. In ancient Mesopotamia, it was more important than wheat in most people's diets. It was the original sole staple of ancient Greece, where some of the earliest Athenian coins were stamped with images of barley sheaves.

The reference to soups and stews is particularly important here from the point of view of the history of 'spoons'. Although, as Fernandez-Armesto (p. 102) notes, "gradually commercial integration of the Mediterranean world in antiquity made it possible for wheat, grown in vast grainlands across Egypt, Sicily and the North African littoral, to become the main food of "classical' civilization", the main advantage of wheat was its being "a peculiarly good source of bread" (FernandezArmesto, p. 110). But people didn't need spoons to eat bread, they needed them to eat "spoon-foods" such as gruel. It is important, therefore, to note Fernandez-Armesto's further comment: "Almost all early cultivators of wheat also grew barley". (p. 109) 
Even more relevant than Fernandez-Armesto's reference to soups and stews is anthropologist Peter Bellwoods' reference to gruels and porridges, in his (2005) book Early Farmers: The Origins of Agricultural Societies (p. 55):

By soon after 7000 BC we witness a common and widespread use of pottery, an item of great significance in allowing the preparation of soft cereal-based foods such as gruels and porridges - foods which seem rather minor to us today but which, for a population consuming mainly gritty bread beforehand, could have opened a door toward early weaning, more rapid population growth, and much less toothache.

A short answer to the question "why spoons?" is, I conjecture, this: because in certain parts of the Earth (such as western Asia) many people came to depend, for survival, on eating hot gruel or porridge. To be able to eat such food people needed something like 'bowls' (which could be put somewhere in a stable position for some time), and something like 'spoons', to transfer the hot food from the 'bowl', in small instalments, into the mouth.

The question: "why not spoons?" arising in relation to Chinese speakers cannot be discussed here in detail, but in a nutshell, my conjecture is this. Cooked rice is not as "liquidy" and not as hot as cooked gruel or porridge made of barley or wheat. Consequently, a bowl of cooked rice could be held in one hand while eating. Consequently, such a bowl had to be reasonably small (and adapted to the shape and size of the hand). The Chinese bowl, while smaller than a typical "European" bowl from which soup and porridge are eaten, is also deeper, certainly deeper than a plate in which soup is (was) served (as in Breughel's painting). It is not easy to hold a plate of soup, as in the Willa Cather example, in one hand, while eating. The practice of eating 'tāng' ('mixed soup', 'soup' with many pieces of solid food) from a bowl held in one hand conforms to the practice of eating rice from such a (hand-held) bowl; as noted by Newman (2004) in Food Culture in China, the use of "spoons" (i.e. 'tāngchí') started with rice, not with soup:

Early cooking began in boiling water, but the popularity of grilling and firepot cookery came into use from the Mongol people (...). About the same time, spoon use for eating rice and cooked dishes began to decline (...). In their place, chopstick use began to increase. (p. 20)

The presence of many solid pieces in a bowl of 'tāng' means that this bowl is usually not as hot to the hand as a bowl of gruel or porridge could be; and the fact that the bowl is small (smaller, though deeper, than a bowl of porridge would be) is also consistent with the practice of holding it in one hand while eating. Accordingly, a 'spoon', with a 'long' (European) handle, is not an appropriate 'tool' to eat 'tāng' with (from a bowl which is close to the eating person's mouth). A 'tāngchí', with a short handle and with a flat-bottomed rounded part, is much better suited to eating 'tāng. (It is also well suited to being used in combination with chopsticks, but this is another story.)

The question of why Chinese has no word matching spoon is closely related to the question of why it has no word matching plate (as in the Willa Cather example, where soup is ladled into the plates). The answer to the second of these questions is that plates are essentially flat, so they are intended to be placed on a flat surface (top of the table). They make sense, therefore, when used in conjunction with a long European 'spoon' ('long' from a Chinese point of view), which also presupposes a flat surface. As the quote from Willa Cather's novel illustrates, in modern English, the three words, soup, spoon and plate, often go together (as do also soup, spoon and bowl). In Chinese, on the other hand, the words that go together are tāng ('mixed soup'), tāngchí (a tool to eat 'tāng' with), and wăn (that is, a 'bowl' which can be held in one hand when full and from which both 'tāng' and rice can be eaten) (Zhengdao Ye, personal communication.)

In an article entitled "A Study of the Ancient Chinese table spoon, chopsticks and fork", Chinese scholar Wang Renxiang (1990) writes: "Seven thousand years ago, there were already bone spoons for traditional grain-eating. When various sorts of soup became used courses in daily meals, the chopsticks were invented to pick up food in hot soup". This is consistent with the hypothesis that "Chinese spoons" were used for rice before they were used for 'soup', and also, that the setting which they presupposed (the bowl near the mouth) goes back to the times when both the "Chinese spoons" and the "Chinese bowls" were used for "traditional grain-eating”. To quote from a review article in Trends in Genetics (Kovach et al., 2007: 578):

More than 10000 years ago, ancient peoples began to gather and consume Oryza rufipogon, an unruly wild grass species (...). that grew in the swamps and marshes throughout tropical and subtropical Asia (...). Through a process of continuous selection of desirable features, these early farmers slowly transformed wild rice into Oryza sativa, which is now the primary source of food and livelihood for more than a third of the world's population.

The connections between the semantics of the word tängchí, the domestication of rice in China and the evolution of Chinese cooking is an interesting subject for in-depth interdisciplinary investigation.

\section{The invention of the 'spoon'}

The invention of the spoon can be compared to the invention of the wheel. There are of course some big differences between the two, but there are also similarities. The two main differences are that the wheel involves a complex technology, whereas the spoon, a relatively simple one; and the second, that the wheel is, potentially, very useful to all human groups, whereas the spoon is not: for example, the Chinese (a sixth part of the world population) find 'tāngchí' more useful than 'spoons' (although they have now been familiar with 'spoons' for a long time).

As noted by Diamond, innovations are either locally invented or borrowed from other societies; and if the technology is complex, they are more likely to be borrowed. For example, "no one thinks that the same peculiar Old World wheel design [a 
solid wooden circle constructed of three planks fastened together] appeared repeatedly by chance at many separate sites of the Old World within a few centuries of each other, after 7 million years of wheelless human history". (p. 255) As Diamond further notes, "the sole wheel of Native American societies (depicted on Mexican ceramic vessels) consisted of a single piece, suggesting a second independent invention of the wheel".

The technology of the 'spoon' is not complex like that of the wheel, so it is likely that the invention of the 'spoon' happened independently in a number of places. It is important to realise, however, that in each case it was a conceptual, and not only technological, innovation. To understand how this invention may have happened, at the conceptual level, we need to put ourselves mentally in the position of the first inventors - those who had not seen any 'spoons' before but came to imagine them, and the whole process of using them, in their heads. The natural semantic metalanguage (NSM) allows us to do that, without attributing to those early Stone Age inventors concepts developed in modern European languages, such as 'container', 'shape', 'liquid', 'solid', and so on.

I think there is a qualitative difference between, on the one hand, an improvisation, such as picking up a shell or a chip of wood to eat with when some food otherwise difficult to eat is in front of us, and on the other, the invention of "a thing of one kind" that could be reproduced according to a stable model fixed in the inventor's mind. Nobody doubts that the invention of the wheel was a momentous conceptual event in human prehistory, and many attribute similar significance to the invention of the needle (which the Neanderthals didn't have but the Cro-Magnons did, and which allowed some groups of early humans, including the Cro-Magnons, to improve their ability to survive in cold climates, cf. Diamond, 1997: 39).

My point is not that the invention of the spoon was comparable in significance to the invention of the wheel or the needle, but rather, that the emergence of the spoon in human prehistory was also a significant conceptual innovation and that the idea underlying this innovation was no less complex and rich (as was also of course the idea behind the emergence of 'tāngchí').

In his book From Hand to Mouth: How we invented knives, forks and chopsticks, James Giblin (1987: 13) writes:

Starting about 1000 B.C., the Egyptians produced small, round bronze spoons with a sharp point at the end of the stems. Perhaps a diner turned the spoon around and used the point to spear pieces of meat and fish. Or perhaps he extracted snails from their shells with it. No one today knows for sure.

Whatever the Egyptians used those small utensils for, it seems clear that the idea behind them was different from the idea of a 'spoon' - and also, from the idea of 'tāngchí'. On the other hand, the 'spoon' found in a burial site near Lucerne, in Switzerland, which was made between 3000 and 2500 BC and which was carved from wood, was indeed a 'spoon' in the sense of the idea explicated here.

According to Giblin, "every spoon consists of two part: the bowl, which contains the solid or liquid food, and the stem, or handle, which the diner grips". As I see it, this definition of what is essential for all 'spoons' is both too broad and too narrow, and it doesn't explain the cultural logic of 'spoons'. Unlike the sharp-ended Egyptian utensils made of bronze, 'spoons' are not for 'solid or liquid food', they are, roughly speaking, for semi-liquid food, and more precisely, for food that can move in the way water can move. I conjecture that they are also, prototypically, for hot food.

If we use NSM as our approximation of the "language of thought" (LOT) of our pre-historical ancestors (cf. Goddard et al., 2014), it is possible to reconstruct, with some plausibility, an identifiable model developed in some individual human minds in western Asia and then Europe which led to the practice of manufacturing 'spoons'. It is also possible to reconstruct a plausible model developed in some individual minds in China which led to the practice of manufacturing 'tāngchí'. In what follows, I will try to reconstruct a possible train of thoughts which may have led to the birth of the first of these two human models. Since I imagine the inventors of 'spoons' to have been (to borrow a phrase from Fernandez-Armesto) 'wheat eaters' and 'barley eaters' rather than 'rice eaters' (or 'maize eaters'), I will assume in this reconstruction that the nourishing food they had in mind was hot gruel of some sort.

PROTO-SPOON: THE BIRTH OF AN IDEA

[a long time ago, somewhere, someone thought like this:]

I want to do something, I can't do it

sometimes when I want to eat something, I can't do it because it is like this:

I can't hold some of it with my hands because this something can move like water moves

I can't hold some of it inside one of my hands, like I can hold some water inside one of my hands for a short time, because this something can be very hot

\section{I want to think about it}

maybe I can eat this something if I do something to it for some time with a thing of one kind this thing of one kind is not here now

it can be here if I do something with my hands to something hard

I want to do it

I want this thing of one kind to be like this:

it has two parts 
one of these two parts is long

I can hold this part with one hand for some time as I want

the other part is like one of my hands can be

when I want there to be a little water inside it for a short time

I can do something with a thing of this kind as I want when it is like this:

this hot something is inside a big thing of another kind

this big thing of another kind is near the place where I am, I can touch it with my hands if I want

this big thing of another kind can be in the same place for some time.

like something can be in the same place for some time if it is on the ground

when it is like this, I can eat this hot something if I do it like this:

I hold the long part of this thing of one kind with one hand for some time

during this time I move this hand in two ways

when I move this hand in one way, the other part of this thing of one kind can be for a short time inside this big thing of another kind because of this

at that time, a little of this hot something inside this big thing of another kind

can be inside this part of this thing because of this, as I want

when I move this hand in another way, this something hot inside this part of this thing can be inside my mouth because of this

I do it like this many times

\section{Conclusions: the cultural logic of 'spoons'}

Needless to say the idea of a 'spoon' did not come out of nowhere. Before 'spoons', there were 'knives', and the idea of holding something in one hand and manipulating it to achieve a certain effect was already well established. Two key conceptual breakthroughs must have preceded the idea - and the technology - of a 'spoon': the appearance of "composite tools" and of "containers" (Boesch, 2012: 235; see also Goddard et al., 2014).

A 'spoon' is a 'composite tool' with two different parts, as are also 'knives' and 'axes', which obviously predated 'spoons' in human prehistory. The idea of a 'long part' which can be held in one hand links 'spoons' with those earlier bipartite human tools (cf. e.g. Fagan, 1998; Tattersall, 2012). The idea of making things with two parts one of which can contain some water (or something like water) builds on earlier technologies involving pottery and pots. But the combination of those older ideas and technological innovations must also be seen as a significant development, and the logic of this combination suggests a particular economic and ecological context, where people often needed to carry small amounts of hot semi-liquid food such as porridge from a stable "big thing" (such as a pot or a bowl) to their mouths.

I have quoted at the outset the statement that "all people of the world use spoons (...) Every human society has spoons of one kind or another". This is clearly not accurate, as the case of Aboriginal Australia - were there are no pots, no bowls and no spoons - illustrates. Aboriginal Australians do of course cook food, but their cooking consists mainly of roasting meat and tubers, and these can be cooked without pots, and eaten without forks, chopsticks or spoons, with hands and fingers.

Aboriginal Australians are hunter gatherers: they don't plant wheat, barley, or other cereals (although they do use seedgrinding implements and bake seeds into cakes, and according for example to Cane (2013: 175), may have "started processing cereals (...) about 10000 years ahead of anybody else on earth"). Presumably, however, in order to cook grains into food such as porridge or gruel people do need pots, in order to share such cooked food with other people, they do need something like bowls, and in order to eat it, they do need something like 'spoons'. (It is true that in the past, in many places, people used to (and in some places, still do) eat such food from a communal bowl, but even for that, 'spoons' are practically necessary.)

A document on the "History of Eating Utensils" produced by California Academy of Sciences states: "Spoons have been used as eating utensils since Paleolithic times". It also says that "it is most likely that prehistoric people used shells or chips of wood as spoons". These two statements may seem to be of a piece, but in fact they are at odds with one another: were people using spoons in Paleolithic times or where they using shells and chips of wood (in a way similar in some respects to the way in which spoons are used now and were used in many places in Neolithic times?)

When the focus is on things rather than concepts, it is indeed impossible to draw a line between 'spoons' and 'sort-of-spoons' there are many shades of grey between a "Puritan" and a shell, or between a carved wooden spoon and a chip of wood. There is no such shading, however, between the concept 'spoon' and concept 'shell' or 'chip of wood'. The invention of the spoon - like the invention of the wheel - is a conceptual breakthrough. Without a clear distinction between things which are made for a purpose, according to a certain blueprint, and things which are merely used for a purpose, with no crystallised creative idea behind them, we can hardly make any firm generalisations about cultural history, prehistory and the history of cooking and eating.

I submit that cultural kinds are based on complex ideas born in individual human minds in the context of particular needs, ideas that have caught on in certain communities and have become embedded in social practices; and that without identifying these ideas we cannot fully understand the practices based on them. 
The idea of a 'spoon' was born in places and at times when soft watery cereal-based foods such as gruels and porridges became available for human consumption and could be eaten hot from a pot or a bowl if one had an appropriate implement to eat it with. Even though, as Peter Bellwood notes, gruels and porridges don't have the significance today that they had eight or nine thousand years ago, the reference to those early gruels and porridges helps us to explain some aspects of 'spoons' as we know them today - and also some aspects of 'tāngchí', which are the product of a different idea and a different cultural and bio-geographical environment. Both the idea of 'spoon' and that or 'tāngchí' can only be understood in the context of particular food cultures which can have very long memories. The Natural Semantic Metalanguage allows us to articulate those ideas with clarity and precision, and to elucidate the cultural logic of different types of artefacts by pinpointing the relevant features of their traditional context of use.

\section{Acknowledgement}

In working on this paper, I greatly benefitted from discussions with Cliff Goddard and Zhengdao Ye, many thanks to them both. I am grateful to Horacio Fabrega and Anna Gladkova for their valuable comments on an earlier version of this paper. I would also like to thank Kathleen Jepson for her helpful observations on the 'post-refrigeration' use of the word spoon. Last but not least, I would like to thank Nick Enfield, whose question: "what is a spoon?" was a point of departure for this study.

\section{References}

Adair, T., 1993. Three Kinds of Kissing - Scottish Short Stories. Harper Collins, London.

Austen, J., 1833. Emma. Richard Bentley, London.

Bellwood, Peter, 2005. First Farmers: the Origins of Agricultural Societies. Blackwell, Oxford.

Boesch, C., 2012. Wild Cultures. Cambridge University Press, Cambridge.

California Academy of Sciences Institute for Biodiversity Science and Sustainability. The History of Eating Utensils. Online exhibit. http://researcharchive. calacademy.org/research/anthropology/utensil/ (accessed 20.01.14).

Cane, S., 2013. First Footprints: the Epic Story of the First Australians. Allen \& Unwin, Sydney.

Cather, W., 1927. Death Comes for the Archbishop. Knopf, New York.

Collins English Dictionary.

Diamond, J., 1997. Guns, Germs and Steel. Norton, New York.

Enfield, N.J., 2014. The Utility of Meaning: What Words Mean and Why. Oxford University Press, Oxford.

Fagan, B.M., 1998. People of the Earth: an Introduction to World Prehistory, ninth ed. Longman, New York.

Fernandez-Armesto, F., 2001. Food: a History. Macmillan, London.

Fillmore, C.J., 1975. An alternative to checklist theories of meaning. PBLS 1, 123-131.

Fillmore, C.J., 1977. Topics in lexical semantics. In: Cole, R. (Ed.), Current Issues in Linguistic Theory. Indiana University Press, Bloomington, pp. 76-138.

Giblin, J., 1987. From Hand to Mouth: How We Invented Knives, Forks and Chopsticks. Harper Collins.

Goddard, C., 2011. Semantic Analysis, second ed. Oxford University Press, Oxford.

Goddard, C., 2012. Semantic primes, semantic molecules, semantic templates: key concepts in the NSM approach to lexical typology. Linguistics 50 (3), 711743 (Special issue on "Lexical Typology", edited by Maria Koptjevskaja-Tamm and Martine Vanhove).

Goddard, C., 2014. Verb classes and valency alternations (NSM approach), with special reference to English physical activity verbs. In: Comrie, B., Malchukov, A. (Eds.), Valency Classes: a Comparative Handbook. Mouton de Gruyter, Berlin (in press).

Goddard, C., Wierzbicka, A., 2014. Words and Meanings: Lexical Semantics Across Domains, Languages, and Cultures. Oxford University Press, Oxford.

Goddard, C., Wierzbicka, A., Fabrega, H., 2014. Evolutionary semantics. Lang. Sci..

Goddard, C., Wierzbicka, A. (Eds.), 1994. Semantic and Lexical Universals - Theory and Empirical Findings. John Benjamins, Amsterdam.

Goddard, C., Wierzbicka, A. (Eds.), 2002. Meaning and Universal Grammar - Theory and Empirical Findings, 2 Vols. John Benjamins, Amsterdam/ Philadelphia.

Gumperz, J.J., 1982. Discourse Strategies. Cambridge University Press, Cambridge, New York.

Kovach, M.J., Sweeney, M.T., McCouch, S.R., 2007. New insights into the history of rice domestication. Trends Genet. 23 (11), $578-587$.

Labov, W., 1978. Denotational structure. In: Farkas, D., Jacobsen, W.M., Todrys, K.W. (Eds.), Papers from the Parasession on the Lexicon. Chicago Linguistic Society, pp. 220-261.

Longman Dictionary of the English Language.

Newman, J.H., 2009[1852]. The Idea of a University. Ashfield, Dublin.

Newman, J.M., 2004. Food Culture in China. Greenwood, Westport, CT.

Oxford English Dictionary. www.oed.com.

Tattersall, I., 2012. Masters of the Planet: the Search for Our Human Origins. Palgrave, New York.

Wang, R., 1990. The study of the ancient Chinese table spoon, chopsticks and fork. Acta Archaeol. Sin. 3.

Wierzbicka, A., 1984. Cups and mugs: lexicography and conceptual analysis. Aust. J. Linguist. 4 (2), $205-255$.

Wierzbicka, A., 1985. Lexicography and Conceptual Analysis. Karoma, Ann Arbor.

Wierzbicka, A., 2003[1991]. Cross-cultural Pragmatics: the Semantics of Human Interaction, second ed. Mouton de Gruyter, Berlin.

Wierzbicka, A., 2014. Imprisoned in English: The Hazard of English as a Default Language. Oxford University Press, New York.

Wilson, B., October 10, 2012. What Your Spoon Says About You. The Atlantic. http://www.theatlantic.com/technology/archive/2012/10/what-your-spoonsays-about-you/263416/ (accessed 07.02.14). 